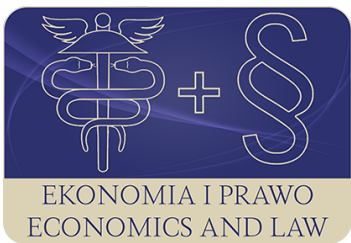

EKONOMIA I PRAWO. ECONOMICS AND LAW

Volume 17, Issue 3, September 2018

p-ISSN 1898-2255, e-ISSN 2392-1625

www.economicsandlaw.pl

ORIGINAL ARTICLE

received 02.01.2018; revised 10.04.2018; accepted 30.09.2018

Citation: Horodecka, A., \& Vozna, L. (2018). Wage inequality and macroeconomic stability: a synergetic approach. Ekonomia i Prawo. Ecomomics and Law, 17(3): 265-277.

doi:10.12775/EiP.2018.019.

\title{
Wage inequality and macroeconomic stability: a synergetic approach
}

\author{
ANNA HORODECKA \\ corresponding author \\ Warsaw School of Economics, Collegium of Economic Analysis, Department of Development \\ Economics and Economic Policy, al. Niepodległości 162, 02-554 Warszawa, Poland \\ ๑horod@sgh.waw.pl
}

LIUDMYLA VOZNA

Independent researcher, Ukraine

๑ludmila.vozna@gmail.com

\begin{abstract}
Motivation: The article is dedicated to the relationship between a level of wage inequality and such an aspect of macroeconomic instability as unemployment. Inequality is connected with structure variety of a relevant economic system. As variety is an important object of complexity study, it makes sense to consider the relationship between wage inequality

and macroeconomic stability in the light of the synergetic and evolutionary theories, which are directly dealing with phenomena of systems complexity, order and stability.

Aim: To present a dispersion (probabilistic) approach in using neoclassical demand and supply curves analysis and, thus, to propose a new definition of the equilibrium problem, which is closer to evolutionary paradigm; with help of the D-S curves, to prove the connection between degree of wage inequality and the general level of unemployment;

to demonstrate two types of extreme macroeconomic instability in their relation with the character of wage inequality, and to regard them from the standpoint of the synergetic conception.

Results: Both situations - very low and very high wage inequality - are related with extreme macroeconomic instability. The first situation can be related not only with general poverty and homogenous, low skilled workforce, but, primarily, with absence of evolutionary change. A very high wage inequality can be related with inflexible labour markets, low level of social mobility and weak social cohesion. These two situations are comparable

with two types of disorder in synergetic conception. With help of the AD-AS curves,
\end{abstract}


the action of macroeconomic synergistic effect is demonstrated; this effect is accompanied by economic growth, decreasing unemployment and the wage levelling. The approach applied in the article confirms some basic propositions of modern macroeconomics and can be used for diminishing the theoretical gap between such opposing interpretations of unemployment as neoclassical and Keynesian.

Keywords: wage inequality; unemployment; instability; evolutionary economics; synergistic effect JEL: B4; D63; E24; J2; J31

\section{Introduction}

The problem of wage inequality is one step away from the problem of income inequality. The latter, in its turn, seems to be eternal and omnipresent as the biblical god-father: it is one of the key topics in endless discussions of scholars, philosophers and moralists, it is used by politicians and preachers in their pathetic speeches, and it sounds in revolutionary hymns as well as during the small disputes of common men in public transport. We are not moralists and it is not our task to answer the question of whether income inequality is good or bad. But as economists we are interested in the issue of economic inequality in its connection with the viability of the socio-economic organism. So the goal of this article deals with the impact of income, i.e. wage, distribution on macroeconomic stability.

It is important to mention that already J. S. Sismondi in the early 1800 s and J. K. Rodbertus (1850) explained capitalistic crises of overproduction by underconsumption of workers. Although these theories were criticized by the overinvestment theory of business-cycle, such a representative of the latter as Mikhail Tugan-Baranovsky (2004, p. 59) in 1900 also noted that mass poverty and the low level of consumption of working classes are among the main reasons of the crises So it is important to take into account the under consumption, i.e. the unequal distribution of income as one of factors, which can deepen a recession and constrain the beginning of economic recovery.

If to take a quick look at the long period tendencies, it is also possible to suppose the correlation between the high rates of income inequality and socio-economic instability. For example, American top 1 per cent incomes peaked in the late 1920s, right before the onset of the Great Depression (Institute for Policy Studies, 2016). During the last decades preceded the Great Recession of 2007-2009, many OECD countries have been characterised by the changing wage structure and increasing inequalities (Damiani et al., 2011, p. 163). The researchers mark that 'income disparities have become so pronounced that America's top 10 per cent now average nearly nine times as much income as the bottom 90 per cent'; since the middle of the 20th century the top 1 per cent of America's income earners have more than doubled their share of the nation's income (Institute for Policy Studies, 2016). So it is no coincidence that some economists speak about the contribution of growing income inequality in USA to the Great Recession (Krugman, 2014b; van Treeck, 2013, pp. 421-448). 
This article is dedicated to wage inequality in its relation with such an aspect of macroeconomic instability as unemployment. As Nobel laureate Paul Krugman (2014a) noted, 'jobs and inequality are closely linked if not identical issues'. In the article this closeness is demonstrated on the basis of traditional curves of demand and supply but using not traditional approach to analysis of market equilibrium they describe. The purpose of the article is to present a dispersion-probabilistic approach in using neoclassical demand and supply curves analysis and, thus, to propose a new definition of the equilibrium problem, which is closer to evolutionary paradigm; with help of the curves of demand and supply, to prove the connection between degree of wage inequality and the general level of unemployment; to demonstrate two types of extreme macroeconomic instability in their relation with the character of wage inequality, and to regard them from the standpoint of the synergetic conception.

\section{Literature review}

As wage inequality has increased during the last decades in many OECD countries, for now there are a very large number of publications dedicated to both the statistical data analysis and the theoretical explanation of this phenomenon. Among the hypotheses designed to explain the increase in wage inequality since the late 1970s are the 'skill-biased technological change' (SBTC) hypothesis and a new technology-based explanation focused on computerization's impact on occupational employment trends and the resulting 'job polarization' (see e.g. Acemoglu \& Autor (2012, pp. 426-463); Autor et al. (1998, pp. 1169-1214); Katz \& Murphy (1992, pp. 35-78)) the theories that emphasize the role of human capital, educational systems and educational inequality (Krueger \& Lindahl, 2001, pp. 1101-1136), the role of institutions (Checchi \& Garcia-Penalosa, 2008, pp. 603-649), the rent sharing theory (Blanchflower et al., 1996, pp. 227-252), and others (Damiani et al., 2011, pp. 163-173; Schmitt et al., 2013).

One of the issues being discussed in literature concerns the earnings of corporate CEOs (Chief Executive Officers) during last decades, in some countries such as USA. For example, researchers mark that real wages for most US workers have increased little if at all since the early 1970s, but wages for the top one per cent of earners have risen 165 per cent, and wages for the top 0.1 per cent have risen 362 per cent (Krugman, 2014a). Today in United States a CEO earns more than 350 times the earnings of an average worker, whereas in 1980 the comparable ratio was closer to 50 (Komlos, 2015, p. 127). Thomas Piketty (2014), in his famous book Capital in the Twenty-First Century, argues that highlevel executives set their own pay, constrained by social norms rather than any sort of market discipline, and he attributes skyrocketing pay at the top to an erosion of these norms; in opinion of Krugman (2014a), in effect, Piketty attributes soaring wage incomes at the top to social and political rather than strictly economic forces. 


\section{Methods}

In general, the article presents a mode of a synthesis between orthodox (mainstream) and heterodox approaches, as it starts from neoclassical instruments such as the curves of demand and supply, but it proposes a new definition of the equilibrium problem, which is closer to evolutionary paradigm.

In the article, the presented method of analysis of market equilibrium, which can be roughly characterized as dispersion-probabilistic, serves as a basic research instrument to consider the problem of wage inequality from the standpoint of synergetic and evolutionary theories. The method of comparative analysis and interdisciplinary approach applied in the article, gives a basis to hypothesize about at least two types of macroeconomic instability in its relation with a level of wage inequality. The theses of the article are argued by references on relevant literature and illustrated with help of figures.

\subsection{Market equilibrium and price dispersion}

Like the neoclassical tradition we would like to use the curves of demand and supply. But in contrast, here the market equilibrium is regarded not as a dead point of equilibrium but as a price dispersion of a definite type.

In our opinion, the curve of demand describes not only the dependence where a definite quantity of demand corresponds to the single price. It is evident that a consumer agrees to buy a certain commodity on the level $q_{1}$, at any price not exceeding the level $p_{1}$. Therefore we can suppose that a score $p_{1}$, corresponding to $q_{1}$ in chart 1 , is the limit of a certain price set, while the demand graph represents the upper frontier of the set of consumers' prices preferences.

The analogical principle is also applicable in relation to the supply curve. It is reasonable to suppose that the sphere of sellers' prices preferences, including the supply curve, also contains some space over it. So we can regard the supply curve as a bottom frontier of the set of sellers' price preferences.

The intersection of these two sets of prices preferences reflects not only the equilibrium price point as the curves of supply and demand do, but also the price dispersion (in chart 1 , this variation is marked by hatching). Here, the demand curve describes the upper frontier of the buyers' prices preferences, and the supply curve describes the lower frontier of the sellers' prices preferences. So we are dealing with price dispersion, where the equilibrium price $p_{e}$ reflects the most frequent (probable) price level (chart l, on the right). The ideal situation must resemble the normal Gaussian distribution; meanwhile a more elastic position of demand and supply curves must correspond to a less price dispersion outlined by these curves, and a less elastic position of demand and supply curves must correspond to a greater level of prices dispersion.

This approach is more realistic because it deals with not only (equilibrium) price, but with a price dispersion, which actually characterizes markets (see e.g. Bayew et al. (2004, pp. 463-496)). Based on the type of price distribution, 
it is possible to judge about a type of market equilibrium, whether it is steady (stable) or unstable (fluctuating). So, for the labor market, the increasing wage inequality can be associated with a shift of the demand curve (or/and supply curve) in the less elastic position (with a possible appearance of a heavy tail in the wage/price distribution; as an example we can consider the case of corporate CEO earning mentioned above) and increasing wage dispersion. As an result, a new wages dispersion should be associated with a higher uncertainty (of prices) and lower stability (of a market), because the probability of deviation of wages (prices, supply and demand) from the mean (equilibrium) point grows. That is why we characterize our approach as dispersion-probabilistic.

\subsection{A step to evolutionary economics}

According to our dispersion-probabilistic approach, it is not correct to define a market equilibrium as a point (of intersection of the curves of demand and supply) but as a structure of certain type. From this point of view, equilibrium means such a functioning of market, which ensures its (market) survival. This also means that it is not reasonable to analogize the market with mechanical systems, comparing the demand and supply with the types of mechanical forces, but rather with living systems. So it is not correct to associate their equilibrium state with such a kind of equilibrium as mechanical or thermodynamic but rather with homeostasis (homeostasis is the term used in biology to describe the internal stability needed for survival of an organism) (see e.g. Vozna (2016, pp. 1-16)). So our approach having based on the neoclassical curves of supply and demand, nevertheless is closer to evolutionary economics, whereas the research program of the latter is based not on mechanistic analogies but on biological ones (Horodecka, 2017, pp. 129-166).

In general, unlike neoclassical economics that defines different optimum points (as the point of market equilibrium, a consumer optimum, a producer optimum, etc.), evolutionary economics takes also into account heterogeneity and structures. Evolution can be perceived as the continuous or erratic/volatile deformation of model structures; similarly with synergetics, the evolutionary economic methodology operates with terms such as evolution, self-organized change, self-transformation and dissipative structures (Horodecka, 2017, pp. 129-166). The dynamic process and variety are key characteristics of evolutionary theory (Nelson \& Winter, 1982).

From the evolutionary point of view, wage dispersion should be considered as an objective characteristic of dynamic process and technological change. As an example it makes sense to consider the idea of wage disparities due to gaps in skills and productivity, and also the 'skill-biased technological change' (SBTC) theory, mentioned above, which explains the increase in wage inequality since the late 1970s and claims that technology raises demand for educated workers, thus allowing them to command higher wages, which in turn increases wage inequality. 
Combining evolutionary ideas and the dispersion-probabilistic method to analysis of market equilibrium, it is possible to conclude that the absence (or weakness) of wage dispersion (on the macro- level) can correspond to the absence of technological change and to highly elastic supply and demand on the labor market. In this situation of wage equality, workforce is comparatively homogeneous and one worker can be easily substituted for another worker.

\section{Results}

\subsection{Between Scylla and Charybdis: two types of disorder}

Historical examples do not say in favor of communist levelling, nor in favor of excessive economic polarization. So Pitirim Sorokin (1947), on the basis of his historical analysis of different social and political systems that existed during last 2600 years, concluded that a human society is always politically, socially and economically stratified, but every society always deals with the struggle between the forces of alignment and the forces of stratification: when the oscillation of the stratification profile in definite direction becomes too strong and sharp, the opposing forces increase their pressure in different ways, and a stratification profile returns to an equilibrium point.

On the basis of Sorokin's studies we can suppose that the both cases the excessively (economically) homogeneous society and the excessively polarized one - are related with instability. This oscillation of a social structure between two poles of economic stratification can be compared with some theses of synergetic and evolutionary conceptions, which concern the processes of disordering and selection.

One of the founders of synergetics, Gregoire Nicolis and Ilya Prigogine (1989), indicated at least two types of disordering. The authors wrote that order looks like a kind of compromise between two antagonistic factors. The first factor is a non-linear process like a chemical one, which continuously and uncoordinatedly sends innovative signals in the form of fluctuations. Another factor resembles the process of transportation because it catches, passes, and stabilizes these signals. The violation of the delicate balance between these two factors leads to the qualitative change of a state that occurs in a system. One of them is a chaotic state in which every element of a system acts independently. In another situation, we are dealing with a homeostatic, frozen state, which is characterized by complete homogeneity and in which all fluctuations are suppressed. Complexity, therefore, is constricted from both sides by two types of disorder.

In our opinion, it makes sense to compare these two types of disorder with the types of selection defined by evolutionary theory. For example, Andersen and Holm (2014, pp. 291-316) consider the three types of selection - directional, stabilizing and diversifying. They are shown in chart 2, where the solid 
lines represent the pre-selection distribution of the characteristic, and the dashed lines represent the distribution of the characteristic after selection.

In opinion of Andersen and Holm (2014), neo-Schumpeterian evolutionary economics has largely been based on the paradigm of directional evolution. This type of evolution moves the mean (an evolutionary relevant characteristic of a population of firms) in a particular direction. However, Andersen and Holm (2014) mark the importance of not only directional selection for evolutionary process, but also stabilizing and diversifying selection. So stabilizing evolution tends to remove any change away from the favored value of characteristic, whereas diversifying evolution promotes the coexistence of different types of behavior within a population and may lead to the emergence of two separate populations.

In our opinion, the point, where the stabilizing selection 'removes any change away' and 'comes to a halt', resembles the type of disorder in description of Nicolis and Prigogine (1989), where we are dealing with a homeostatic, frozen state, which is characterized by complete homogeneity, and in which all fluctuations are suppressed. In its turn, the diversifying evolution resembles the second type of disorder that is characterized as a chaotic state in which every element of a system acts independently. In general, the society with complete economic equality and the economically polarized society are comparable with these two types of disorder (or selection) respectively. It means that socio-economic systems, approaching to one of these poles, are approaching to the high level of uncertainty and instability (in the sense of their further evolution and survival).

\subsection{Inequality and unemployment from a synergistic point of view}

Synergistic effect is an effect arising as a result of interaction between two or more elements (of a system) that produces an effect greater than the sum of their individual effects. The synergistic factor of economic growth is interpreted here as such an increase of openness and, thus, interaction among economic system components (sectors, regions), which leads to economic growth and is also followed by the reduction of differences between these components in prices, wage rates, profit rates, productivity, etc.

By applying the same idea (about connection between price dispersion and the slopes of the D-S curves) for the macroeconomic level, it is possible to demonstrate the synergistic effect of economic growth with the help of ADAS curves. If both the aggregate demand and aggregate supply are comparatively inelastic, alongside with other factors, it likely means a weak interaction between segments of macroeconomics system, i.e. a weak (market) synergy. At the same time, the less elastic the slope of the curves of demand and supply (following the logic above), the larger price dispersion is. So by shifting the demand and supply curve to the more elastic position, we reduce the price dispersion and shift the equilibrium point in the direction of output growth. 
Chart 3.1 demonstrates the economic growth without the synergistic effect, chart 3.2 demonstrates it with such an effect: the removal of the curves of aggregate demand and supply in the more elastic position (if the area of the dispersion triangle is constant) leads to the reduction of a price variation and shifts the equilibrium level of aggregate product to the right (if the shaded area in the left chart is equal to the shaded area in the right chart). The minimal (ideally, zero) level of such a variation means the exhaustion of the synergistic effect of economic growth.

If to use this illustrative method for a labor-market, it would be even a more expressive example. In Chart 4, the supply and demand curves outline the dispersion (set) of wages. If the hatched area in Chart 4 is constant, the removal of supply and demand curves in the more elastic position means the shift of the equilibrium point on the right, i.e. it is accompanied by the growth of employment. The removal of the curves in a less elastic position means the shift of equilibrium point on the left, i.e. the reduction of equilibrium employment level. In other words, the excessive growth of wage differentiation (ceteris paribus) decreases the general level of employment, whereas the reduction of this differentiation has to increase the level employment.

In general, having based on this approach we can make the following theoretical assertion-comments.

1. Despite the limits of our approach, it reveals the relationship between rates of unemployment and wage inequality. Our theoretical conclusion is coherent with some data analysis researches. For example, Checchi and Garcia-Penalosa (2008), on the basis of deep data analysis, made conclusions about the positive direct correlation between unemployment and inequality, and about the evidence of a trade-off between unemployment and income equality; according to their calculations, an increase in unemployment of 1 percentage point is associated with an increase in Gini of 1 point.

2. The two extreme types of labor-market equilibrium (more correctly, nonsteady state) reflect, in some rate, the situations with different rates of income inequality. The first type corresponds to the situation with perfect equality; it can characterize the small, static and closed system. The opposite situation, the excessive inequality (too concave Lorenz curve) is very negative for stability of institutions (e.g. private property) and, thus, for the economic growth too.

3. In Chart 4.2, the maximal level of employment can be reached if to shift the curves of supply and demand on the right, in the maximal elastic position. However, in this case the wage dispersion equals zero. It means that in this point a synergistic effect exhausts and also evolution 'comes to halt'. So our synergetic model is coherent with the fact, that under conditions of dynamic (evolutionary) economy the actual level of employment should be lower than potential one.

4. For the labor market, the synergistic effect can be explained from both the technological and institutional points of view. So, if the high wage ine- 
quality is the result of differences in productivity, it can also be caused by low technological synergy related with the weak diffusion of innovations.

5. From the institutional point of view, as the example of the synergistic effect in the labor market it is possible to consider the phenomenon of social cohesion. So, according to researchers, less equal societies tend to be less cohesive (see Bertelsmann Stiftung (2017)).

6. As the symptoms of the weakening of the synergistic effect in labor markets, it makes sense to consider the tendencies of the decreasing role of trade unions (see Checchi \& Garcia-Penalosa (2008, pp. 603-649)) and the mentioned above increasing CEO earnings during the last decades.

7. Our approach can be considered as the attempt to harmonize so opposing theories of unemployment as neoclassical and Keynesian: the neoclassical recommendation to reduce wages for reducing unemployment does not seem to be effective in the case when its application is not accompanied (leads to) by contraction of the gap between groups of employees with significantly high wages and employees with very low wages; in this case the fiscal policy influencing the income distribution, as a recovering remedy, can be more effective.

\section{Conclusion}

The presented dispersion-probabilistic approach in using the neoclassical curves of demand and supply proposes a new definition of the equilibrium problem, which is closer to evolutionary and synergetic paradigms. So this approach should be regarded as a mode of the synthesis of orthodox (neoclassical) and heterodox (evolutionary) economics.

With help of the curves of demand and supply, and using the dispersion (probabilistic) method to analysis of market equilibrium, it is possible to prove the connection between degree of wage inequality and the general level of unemployment.

Both situations - the very low wage inequality and the very high wage inequality - are related with low macroeconomic stability. The very low wage inequality can be related not only with general poverty, homogenous low skilled workforce and weakly segmented labor markets, but, primarily, with absence of evolutionary change. The very high wage inequality can be related with extremely closed and inflexible labor markets, the relatively low level of social mobility and very weak social cohesion. In other words, this type of (macroeconomic) instability can be connected with the absence of macroeconomic and social synergy. These two situations - of complete wage equality and extreme polarization - can be compared with the two types of disorder in the synergetic conception.

The presented approach can be used for diminishing the theoretical gap between such opposing interpretation of unemployment as neoclassic and Keynesian. To sum up, the synergetic approach is perspective for the cor- 
rect combination of different theoretical recommendations, every of which composes the additional face of such a brilliant as economic science.

\section{References}

Acemoglu, D., \& Autor, D. (2012). What does human capital do? A review of Goldin and Katz'sthe race between education and technology. Journal of Economic Literature, 50(2). doi:10.1257/jel.50.2.426.

Andersen, E.S., \& Holm, J.R. (2014). The signs of change in economic evolution. Journal of Evolutionary Economics, 24(2). doi:10.1007/s00191-014-0350-z.

Autor, D.H., Katz, L.F., \& Krueger, A.B. (1998). Computing inequality: have computers changed the labor market? Quarterly Journal of Economics, 113(4). doi:10.1162/003355398555874.

Bayew, M.R., Morgan, J., \& Scholten, P. (2004). Price dispersion in the small and in the large: evidence from an internet price comparison site. Journal of Industrial Economics, 52(4).

Bertelsmann Stiftung. (2017). Social cohesion radar project. Retrieved 27.03.2017 from https://www.bertelsmann-stiftung.de.

Blanchflower, D.G., Oswald, A.J., \& Sanfey, P. (1996). Wages, profits and rent-sharing. QuarterlyJournal of Economics, 111(1). doi:10.2307/2946663.

Checchi, D., \& Garcia-Penalosa, C. (2008). Labor market institutions and income inequality. Economic Policy, 56. doi:10.1002/9781444307238.chl.

Damiani, M., Hölscher, J., \& Pompei, F. (2011). Labour market inequalities and the role of institutions. European Journal of Comparative Economics, 8(2).

Horodecka, A. (2017). The methodology of evolutionary and neoclassical economics as a consequence of the changes in the concept of human nature. Argumenta Oeconomica, 39(2). doi:10.15611/aoe.2017.2.06.

Institute for Policy Studies. (2016). Income inequality. Retrieved 27.03.2017 from http://inequality.org.

Katz, L.F., \& Murphy, K.M. (1992). Changes in relative wages, 19631987: supply and demand factors. Quarterly Journal of Economics, 107(1). doi:10.2307/2118323.

Komlos, J. (2015). What every economics student needs to know and doesn't get in the usual principles. New York: Routledge. doi:10.4324/9781315698236.

Krueger, A.B., \& Lindahl, M. (2001). Education for growth: why and for whom? Journal of Economic Literature, 39 (4). doi:10.1257/jel.39.4.1101.

Krugman, P. (2014a). Why we're in a new gilded age. Retrieved 27.03.2017 from http://www.nybooks.com.

Krugman, P. (2014b). The populist imperative. Retrieved 27.03.2017 from https:// www.nytimes.com.

Nelson, R.R., \& Winter, S.G. (1982). An evolutionary theory of economic change. Cambridge-Massachusetts-London: The Belknap Press of Harvard University Press. 
Nicolis, G., \& Prigogine, I. (1989). Exploring complexity: an introduction. New York: W.H. Freeman.

Piketty, T. (2014). Capital in the twenty-first century. Cambridge-Massachusetts-London: The Belknap Press of Harvard University Press.

Rodbertus, K. (1898 (1850)). Overproduction and crises. London: Swan Sonnenschein \& Co.

Schmitt, J., Shierholz, H., \& Mishel, L. (2013). Don't blame the robots. Retrieved 27.03.2017 from http://www.epi.org.

Sorokin, P. (1947). Society, culture, and personality: their structure and dynamics. New York-London: Harper \& Brothers Publishers.

Tugan-Baranovsky, M. (2004). Industrial crises. Kiev: Naukova Dumka.

van Treeck, T. (2013). Did inequality cause the U.S. financial crisis? Journal of Economic Surveys, 28(3). doi:10.1111/joes.12028.

Vozna, L. (2016). The notion of entropy in economic analysis: the classical examples and new perspectives. Journal of Heterodox Economics, 3(1). doi:10.1515/ jheec-2016-0001.

Voznaya, L. (2005). Temporal physics in financial catastrophes forecast. Voprosy Economiki, 8.

\section{Acknowledgements}

Author contributions: authors have given an approval to the final version of the article. Authors contributed to this work equally.

Funding: this research was fully funded by the Warsaw School of Economics.

Note: the results of this study were presented at 9th International Conference on Applied Economics Contemporary Issues in Economy (June 22-23, Torun, Poland). 


\section{Appendix}

Chart 1.

Market equilibrium and price dispersion
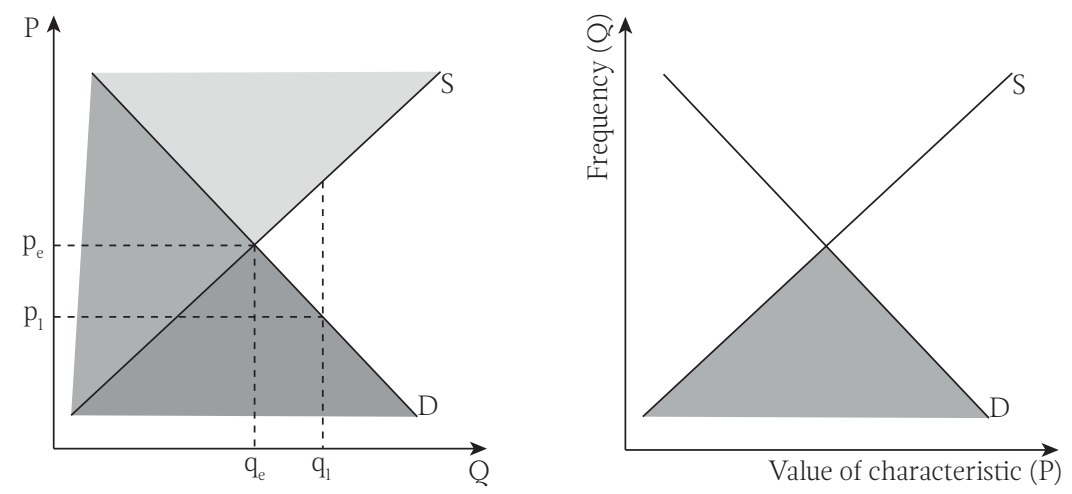

Source: Own preparation based on Voznaya (2005, p. 27).

\section{Chart 2.}

Three types of pure selection

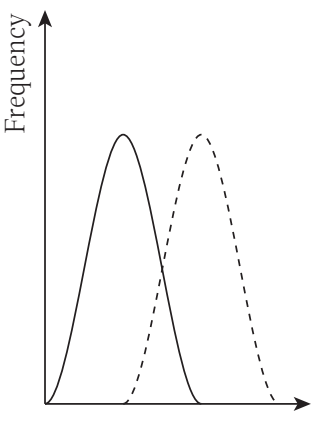

2.1. Pure directional selection

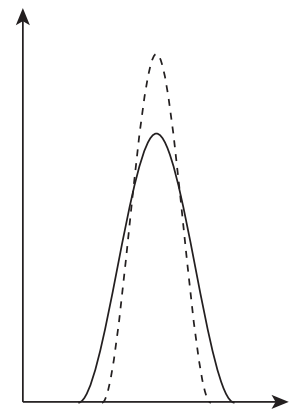

2.2. Pure stabilizing selection

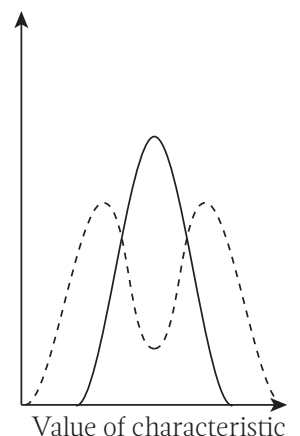

2.3. Pure diversifying selection

Source: Andersen \& Holm (2014, p. 292). 


\section{Chart 3.}

\section{The macroeconomic growth}

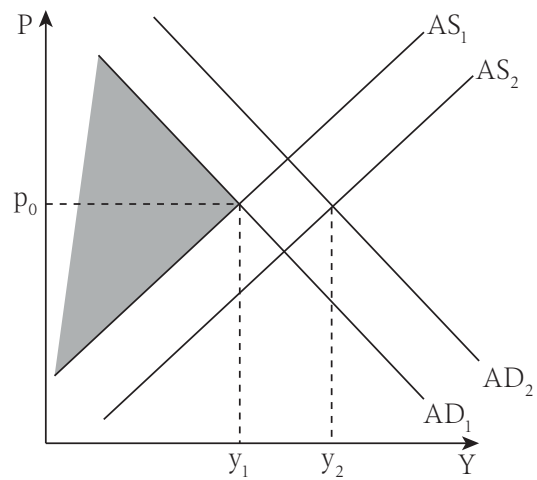

3.1. The economic growth without synergistic effect

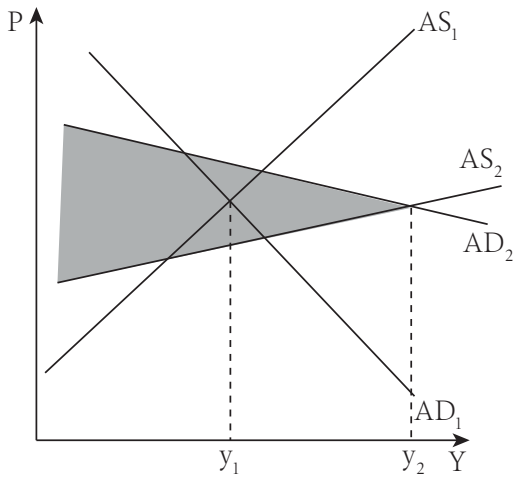

3.2. The economic growth with synergistic effect

Source: Own preparation based on Voznaya (2005, p. 40).

\section{Chart 4.}

The synergistic effect in the labour market

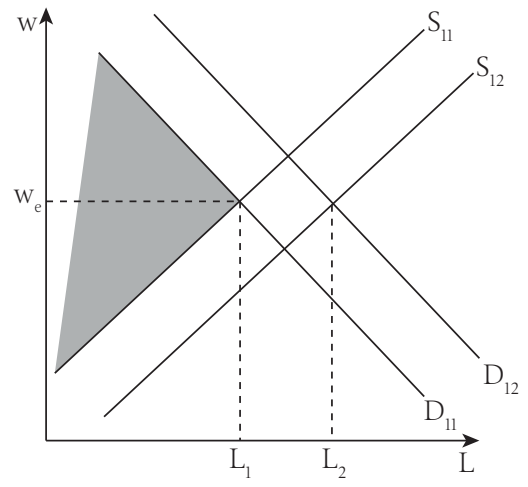

4.1. The growth of employment without synergistic effect

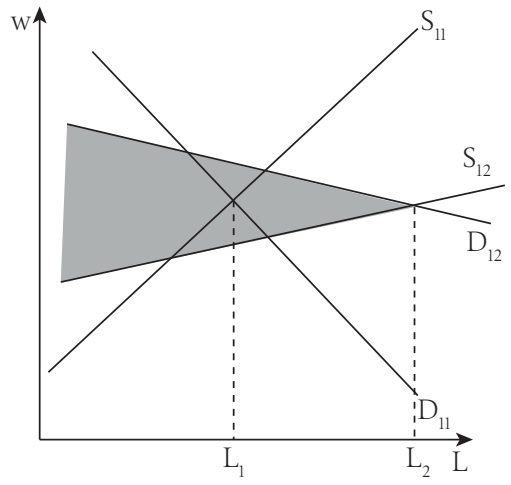

4.2. The growth of employment with synergistic effect

Source: Own preparation based on Voznaya (2005, p. 40). 
